\title{
Incidence, Contributing Factors and Outcomes of Antepartum Hemorrhage in Jimma University Specialized Hospital, Southwest Ethiopia
}

\author{
Nega Chufamo ${ }^{1}$, Hailemariam Segni2,", Yibeltal Kiflie Alemayehu ${ }^{3,4}$ \\ ${ }^{1}$ Department of Obstetrics and Gynecology, School of Medicine, \\ College of Medicine and Health Sciences Arba Minch University, Ethiopia \\ ${ }^{2}$ Department of Obstetrics and Gynecology, School of Medicine, College of Health Sciences, Jimma University, Ethiopia \\ ${ }^{3}$ Department of Health Systems Management, School of Public Health, College of Health Sciences, Jimma University, Ethiopia \\ ${ }^{4}$ Department of Global Community Health and Behavioral Sciences, School of Public Health and Tropical Medicine, \\ Tulane University, USA
}

Copyright (C) 2015 by authors, all rights reserved. Authors agree that this article remains permanently open access under the terms of the Creative Commons Attribution License 4.0 International License

\begin{abstract}
Background: Antepartum haemorrhage complicates three to five percent of pregnancies contributing to perinatal and maternal morbidity and mortality. Timely access to quality obstetric services is the major determinant of both maternal and newborn outcomes after antepartum haemorrhage. In Ethiopia, the magnitude and consequences of antepartum haemorrhage are not well studied. The objective of this study was to determine the incidence, factors associated with and maternal and perinatal outcomes of antepartum haemorrhage in Jimma University Specialized Hospital. Methods: A hospital-based prospective cohort study was conducted in Jimma University Specialized Hospital, from January 1 to December 31, 2013. Data were collected by reviewing medical records and interviewing mothers. Cumulative incidence of antepartum hemorrhage among mothers who gave birth and odds of adverse outcomes among mothers with and without antepartum hemorrhage were calculated. Odds ratio was calculated to estimate the effect of antepartum hemorrhage on maternal and new born adverse outcomes. Results: Between January and December 2013, 3854 women gave birth in JUSH. The incidence of antepartum hemorrhage was $5.1 \%(n=195)$ in 2013. The major causes of antepartum hemorrhage were abruptio placentae and placenta previa occurring in $127(65.1 \%)$ and $52(26.7 \%)$ of cases, respectively. Six (3.1\%) of the patients with antepartum hemorrhage died. Of the 206 babies born, $63(30.6 \%)$ were stillborn and additional 13 (6.3\%) newborns died during the first seven days of life making perinatal mortality rate of $36.9 \%$. Conclusion: Antepartum hemorrhage is a common complication of pregnancy and cause of maternal and perinatal mortality in Jimma University Specialized Hospital. The risk of adverse outcomes is very high compared to other countries. Efforts to improve access and quality of comprehensive emergency obstetric care services are required.
\end{abstract}

Keywords Antepartum Hemorrhage, Placenta Previa, Abruptio Placentae, Maternal Mortality, Perinatal Mortality

\section{Introduction}

Adverse pregnancy outcomes including maternal and perinatal morbidity and mortality constitute major public health problems in the developing world. The risk of dying from maternal causes is 100 times higher for women in developing countries compared to those in developed countries. Developing countries contribute to $99 \%$ of the world's maternal deaths $(1,2)$. In 2013, sixty percent of Sub-Saharan African countries had a Maternal Mortality Ratio (MMR) of above 400 maternal deaths per 100,000 live births (3). Ethiopia has one of the world's highest MMRs at 676 maternal deaths per 100,000 live births in 2011(4), showing no reduction from its 2005 level of 673 maternal deaths per 100,000 live births (5). Despite reductions observed during the last decade, perinatal mortality also remained high compared to other developing and developed countries (6). For the period 2006 to 2011, the average perinatal mortality rate in Ethiopia was 46 perinatal deaths per 1,000 pregnancies of seven or more months of gestation (4). Obstetric haemorrhage remains one of the major causes of maternal deaths (7-10), and one of the primary obstetric causes of perinatal mortality (11-13). Antepartum hemorrhage (APH), bleeding from the genital tract of a pregnant mother with a viable fetus before the onset of labour, complicates $3.5 \%$ of pregnancies and it constitutes one of the reasons for emergency hospital visits among pregnant women $(14,15)$. Abruptio placentae and placenta previa are the major causes of APH $(16,17)$. Even though a number of obstetric and non-obstetric situations are identified as risk factors for APH (17-21); it still remains a predominantly unpredictable condition (14). Access to quality basic and emergency obstetric care services remains 
the major plausible explanation for disparities in the risk of maternal and perinatal mortality and morbidity from APH in different parts of the world (22). Once it occurs, hemorrhage is likely to be fatal to the mother or her baby in situations where actions cannot be taken immediately to stop further bleeding, replace excessive blood loss, and prevent fetal complications $(15,23,24)$. Evidence shows that variability in the burden of APH is primarily a result of variations in outcomes instead of variations in incidence, suggesting the vital role that improved obstetric care can play in addressing the issue. Studies from Africa have shown comparable prevalence of causes of APH compared to those from Europe and the United States; however, maternal and newborn outcomes of APH varied vastly between developing and developed countries (25). Information regarding the magnitude, causes and consequences of APH is limited in Ethiopia. A study from Hawassa University Hospital, a referral hospital in Southern Ethiopia, conducted on placenta previa and abruptio placentae patients who visited the hospital between January 2006 and December 2012 reported perinatal mortality rate of $50 \%$. This research was indicative of the high incidence of adverse pregnancy outcomes after APH (26). The aim of this study was, therefore, to determine the magnitude, contributing factors and outcomes of women presenting with APH in Jimma University Specialized Hospital (JUSH).

\section{Materials and Methods}

Study Setting: The study was conducted from January 1 , 2013 to December 31, 2013 in JUSH, a teaching hospital located in Jimma town of Oromia Regional State, Ethiopia. Located $357 \mathrm{~km}$ from Addis Ababa, JUSH is the only specialized referral hospital in the South Western region of Ethiopia. The hospital has a predominantly rural catchment population of 15 million people for tertiary level care. In 2004 Ethiopian fiscal year (2011/2012 GC) the hospital has provided service to 12,266 emergency cases, 136,332 outpatient clients and 18,478 admitted patients. The labor ward has given services to 3,775 deliveries among which $927(24.6 \%)$ were cesarean deliveries. JUSH is also serving as a clinical postgraduate specialty teaching hospital for different specialties including Obstetrics and Gynecology and Pediatrics \& Child Health, since 2005. The Department of Obstetrics and Gynecology has a labor ward with six beds in first stage room, four delivery couches in the second stage room, three beds in recovery unit and forty beds in maternity ward, along with two operation rooms. The ward is staffed with eight obstetrics and gynecology specialists, 25 midwives, 16 clinical nurses, and 33 residents of different years (levels) of study.

Study Design: A hospital-based prospective cohort study design was employed. All women who were admitted to the labor/maternity ward during the study period were followed until discharge from the hospital or seven days after giving birth, whichever came first. Women presenting with uterine rupture were excluded because of difficulties to ascertain the diagnosis of antepartum hemorrhage.

Measures: Cumulative incidence of APH was determined by using the number of cases identified during the one year study period and the aggregate number of mothers who were admitted to the maternity/labor ward of JUSH. Patient characteristics, maternal mortality, and perinatal mortality were measured among APH cases.

Data Collection: Data were collected by reviewing medical records and interviewing mothers. A pretested structured questionnaire was used to collect data regarding patient characteristics, causes of APH, maternal outcomes and newborn outcomes for each APH case. Data on APH cases was collected by eight second year obstetrics and gynecology residents who were trained on how to complete the data collection questionnaire during patient follow-up period. Newborn outcome for neonates referred to neonatology unit was obtained by reviewing patient records and registration books in the neonatology unit. Aggregate data on total number of mothers who gave birth in the hospital during the study period was obtained by reviewing registration books of the labor/maternity ward. The data collection process was supervised by one of the principal investigators, a resident in the department during the data collection period.

Data Management and Analysis: Data was checked for completeness, cleaned and entered into SPSS version 16.0 on a daily basis. The final dataset was analyzed using the same software using descriptive statistical packages and binary logistic regression was also used.

Ethics: Before data collection, Ethical Review Committee of the College of Public Health and Medical Sciences, Jimma University has approved this study. Written consent was obtained from all APH patients included in the study.

\section{Results}

Between January 1 and December 31, 2013, a total of 3,854 women gave birth in JUSH. One hundred ninety five of them were diagnosed to have APH showing a cumulative incidence of $5.1 \%$ in 2013. The distribution of socio-demographic characteristics among women with APH broadly reflects the population composition of reproductive age women in the catchment area; majority of the mothers included in this study were Oromos (81\%), Muslims (69.2\%), housewives (57.4\%) married (96.9\%), and illiterate (45.1\%). The average age of the women was 26.6 years with standard deviation of 5.9 years. Two third of the mothers were in the age range of 21 and 34 (Table 1). 
Table 1. Socio-demographic characteristics of mothers with APH, JUSH, 2013

\begin{tabular}{|c|c|c|c|}
\hline Variables & Categories & Frequency & Percent \\
\hline \multirow{3}{*}{ Age in years } & 20 or younger & 38 & 19.5 \\
\hline & $21-34$ & 130 & 66.7 \\
\hline & 35 or older & 27 & 13.8 \\
\hline \multirow{4}{*}{ Ethnicity } & Oromo & 158 & 81.0 \\
\hline & Amhara & 14 & 7.2 \\
\hline & Guragie & 9 & 4.6 \\
\hline & Others & 14 & 7.2 \\
\hline \multirow{3}{*}{ Religion } & Muslim & 135 & 69.2 \\
\hline & Orthodox & 49 & 25.1 \\
\hline & Protestant & 11 & 5.6 \\
\hline \multirow{5}{*}{ Occupation } & House wife & 112 & 57.5 \\
\hline & Farmer & 56 & 28.7 \\
\hline & Civil servant & 11 & 5.6 \\
\hline & Merchant & 10 & 5.1 \\
\hline & Others & 6 & 3.1 \\
\hline \multirow{5}{*}{$\begin{array}{l}\text { Educational } \\
\text { status }\end{array}$} & Illiterate & 88 & 45.1 \\
\hline & Read and write only & 7 & 3.6 \\
\hline & Attended grades 1-8 & 57 & 29.2 \\
\hline & Attended grades 9-10 & 22 & 11.3 \\
\hline & $\begin{array}{c}\text { Attendedgrade } 10 \text { or } \\
\text { above }\end{array}$ & 21 & 10.8 \\
\hline \multirow{3}{*}{ Marital status } & Married & 189 & 96.9 \\
\hline & Widowed & 4 & 2.1 \\
\hline & Single & 2 & 1.0 \\
\hline \multirow{2}{*}{ Address } & Jimma town & 58 & 29.7 \\
\hline & Out of Jimma & 137 & 70.3 \\
\hline \multirow{4}{*}{$\begin{array}{l}\text { Gestational } \\
\text { Age at time of } \\
\text { delivery }\end{array}$} & $28-33$ wks & 37 & 19.0 \\
\hline & 34 to $36 \mathrm{wks}$ & 54 & 27.7 \\
\hline & 37 to 41 wks & 103 & 52.8 \\
\hline & $\geq 42 \mathrm{wks}$ & 1 & 0.5 \\
\hline
\end{tabular}

\section{Causes of APH}

Abruptio placentae and placenta previa were the major causes of APH established as final diagnosis in 127 (65.1\%) and $52(26.7 \%)$ of APH patients, respectively. Other causes including leech infestation and unknown causes accounted for $16(8.2 \%)$ of the cases. The incidence of abruptio placentae and placenta previa was $3.3 \%$ and $1.4 \%$ among mothers who gave birth in JUSH in 2013.

Among patients with placenta previa, $41(78.9 \%)$ had placenta previa totalis. Placenta previa partialis and placenta previa marginalis posterior were the second most common type of placenta previa, each accounting for $5(9.6 \%)$ of placenta previa patients . There was only one $(1.9 \%)$ mother with low lying placenta; and no mother was diagnosed with placenta previa marginal anterior. Of the 127 patients with abruptio placentae, just over half $(52 \%)$ had grade 1 or grade 0 according to Sher's grading criteria (Grade I (Retrospective) Not recognized clinically before delivery: small retroplacental Haematoma discovered on maternal surface of placenta after delivery, No APH; Grade II mild vaginal bleeding, uterine tenderness and tetany, No fetal distress, no maternal shock; Grade III Severe vaginal bleeding, uterine tenderness and tetany, fetal distress then death, maternal shock, according to DIC: IIIa: Without DIC, IIIb:With DIC) diagnosed in $34(26.8 \%)$ and $32(25.2 \%)$ of patients, respectively (Figure 1 and Figure 2).

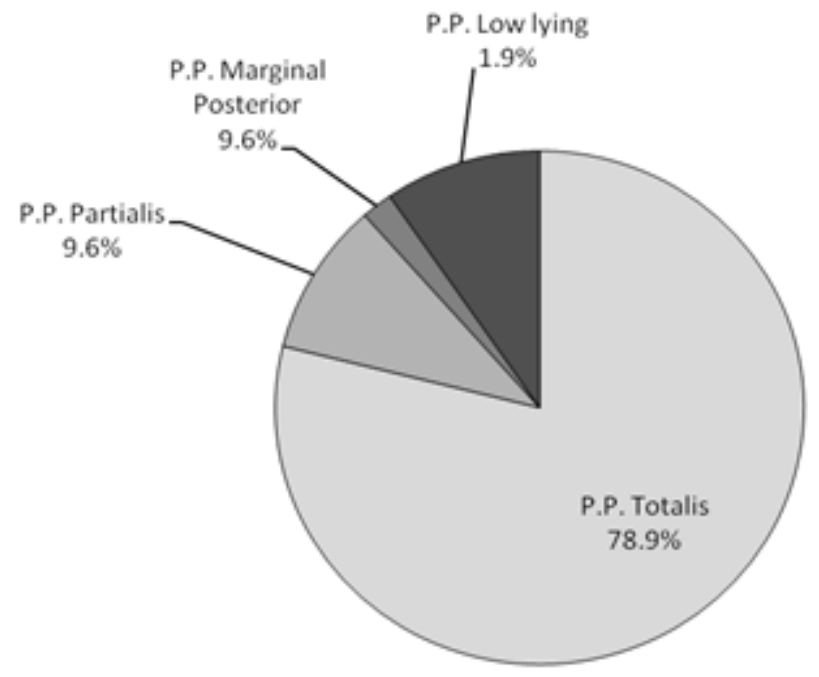

Figure 1. Prportion of women experiencing Placenta Previa by type $(\mathrm{n}=52)$



Figure 2. Prportion of women experiencing Abruptio Placentae by grade $(\mathrm{n}=127)$

\section{Access to and Quality of Services}

Majority, 158 (81\%), of the mothers with APH had at least one prenatal care visit to a health facility. Fifteen $(28.8 \%)$ of patients with placenta previa and $19(15 \%)$ of those with abruptio placentae had no prenatal visits. One hundred sixty three $(83.6 \%)$ of the patients were referred from another health facility. At the time of presentation, 138 (70.8\%) of them had vaginal bleeding while the rest had only concealed bleeding (concealed bleeding is when a patient's bleeding is not recognized clinically before delivery but is diagnosed to have abruptio placentae after delivery of the baby and placenta with small retroplacental hematoma discovered on maternal surface of placenta). For patients with revealed vaginal bleeding, the median time of presentation from start of vaginal bleeding to time of assessment by a physician was 12 hours (IQR: 5 to 24 hours). On presentation, 75 (38.5\%) of the mothers had excessive vaginal bleeding (as described by treating physicians) and 48 (24.6\%) had deranged vital signs (hypotension: blood pressure less than 90/60 mlli meter 
mercury, tachycardia: pulse rate more than 100 beats per minute). Data on whether an intravenous (IV) line was secured or not on presentation was available for 117 mothers with revealed vaginal bleeding, all of which were referred from another health facility. Among these mothers IV line was secured on referral only for 29 (24.8\%). (Table 2 )

Cesarean delivery (CD) was the common mode of delivery used in $106(54.4 \%)$ of APH patients. It was employed in $49(94.2 \%)$ mothers with placenta previa of which 39 (79.6\%) were done as emergency. Fifty four (42.5\%) of mothers with abruptio placentae delivered by CD; $21(16.5 \%)$ delivered with instrumental delivery, forceps being the commonest. Non-reassuring fetal heart beat pattern (bradycardia) was the major indication for $\mathrm{CD}$ in mothers with abruptio placentae documented in $36(66.7 \%)$ of cases. (Table 2)

Table 2. Healthcare Services to mothers with APH, JUSH, 2013

\begin{tabular}{|c|c|c|c|}
\hline $\begin{array}{l}\text { Characteristics of } \\
\text { care }\end{array}$ & Categories & Number & Percent \\
\hline \multirow{3}{*}{$\begin{array}{l}\text { Mode of delivery } \\
\quad(\mathrm{n}=195)\end{array}$} & Cesarean Delivery & 106 & 54.4 \\
\hline & $\begin{array}{l}\text { Spontaneous Vaginal } \\
\text { Delivery }\end{array}$ & 65 & 33.3 \\
\hline & Instrumental Delivery & 24 & 12.3 \\
\hline \multirow{2}{*}{$\begin{array}{l}\text { Type of cesarean } \\
\text { delivery }(\mathrm{n}=104)\end{array}$} & Emergency & 91 & 87.5 \\
\hline & Elective & 13 & 12.5 \\
\hline \multirow{2}{*}{$\begin{array}{l}\text { Prior obstetric } \\
\text { care }(n=195)\end{array}$} & Had prenatal care & 158 & 81.0 \\
\hline & $\begin{array}{c}\text { Referred from another } \\
\text { health facility }\end{array}$ & 163 & 83.6 \\
\hline \multirow{2}{*}{$\begin{array}{l}\text { Blood transfusion } \\
\quad(\mathrm{n}=195)\end{array}$} & $\begin{array}{l}\text { Blood transfusion } \\
\text { indicated }\end{array}$ & 98 & 50.3 \\
\hline & $\begin{array}{l}\text { Blood transfused (at } \\
\text { least one unit) }\end{array}$ & 36 & 18.5 \\
\hline \multicolumn{2}{|c|}{$\begin{array}{l}\text { IV line secured on referral (data available for } \\
117 \text { referred cases only) }\end{array}$} & 29 & 24.8 \\
\hline \multicolumn{2}{|c|}{$\begin{array}{c}\text { Median time of bleeding to presentation at } \\
\text { health facility }\end{array}$} & \multicolumn{2}{|c|}{$\begin{array}{c}12 \text { hours } \\
\text { (IQR: } 5 \text { to } 24 \text { hours) }\end{array}$} \\
\hline
\end{tabular}

\section{Perinatal Outcomes}

A total of 206 babies were born to 195 mothers. One hundred eighty four (89.3\%) were singleton babies; the rest $22(10.7 \%)$ were twins. Of the total 206 babies born, 143(69.4\%) were liveborns and $63(30.6 \%)$ were stillborn. An additional 13 neonates (6.3\%) died within seven days of life after referral to Neonatal Intensive Care Unit (NICU). Overall, perinatal mortality rate among births to mothers with APH was $36.9 \%$. The prevalence of low birth weight among all births was $35 \%$.



Figure 3. Magnitude of perinatal deaths among APH cases, JUSH, 2013

The major reason for referral to NICU was preterm delivery $27(57.4 \%)$. The major cause of neonatal death in NICU was respiratory failure accounting for $9(69.2 \%)$ of the total NICU deaths during the first seven days of life among referred neonates.

Table 3. Perinatal Outcomes, newborns born to mothers with APH, JUSH, 2013

\begin{tabular}{|c|c|c|c|c|c|c|}
\hline Variables & Categories & \# of newborns & $\begin{array}{c}\text { \# of still } \\
\text { births }\end{array}$ & $\begin{array}{c}\text { \# of early neonatal } \\
\text { deaths }\end{array}$ & $\begin{array}{c}\text { \# of perinatal } \\
\text { deaths }\end{array}$ & $\begin{array}{c}\text { Percent } \\
\text { perinatal death }\end{array}$ \\
\hline \multicolumn{2}{|c|}{ All newborns } & 206 & 63 & 13 & 76 & 36.9 \\
\hline \multirow{3}{*}{ Cause of APH } & Placenta Previa & 55 & 15 & 2 & 17 & 30.9 \\
\hline & Abruptio Placentae & 135 & 48 & 10 & 58 & 43.0 \\
\hline & Other Causes/Unknown & 16 & 0 & 1 & 1 & 6.3 \\
\hline \multirow{2}{*}{ Address } & Jimma & 61 & 14 & 1 & 15 & 24.6 \\
\hline & Out of Jimma & 145 & 49 & 12 & 61 & 42.1 \\
\hline \multirow{2}{*}{ Maternal Age } & Less than 35 years & 176 & 51 & 10 & 61 & 34.7 \\
\hline & 35 years or older & 30 & 12 & 3 & 15 & 50.0 \\
\hline \multirow{2}{*}{$\#$ of fetuses } & Single & 184 & 53 & 10 & 63 & 34.2 \\
\hline & Twin & 22 & 10 & 3 & 13 & 59.1 \\
\hline \multirow{2}{*}{ Gestational Age } & Preterm (<37 wks) & 100 & 35 & 10 & 45 & 45.0 \\
\hline & Term $(>=37 \mathrm{wks})$ & 106 & 28 & 3 & 31 & 29.2 \\
\hline
\end{tabular}


Binary logistic regression with contributing factors to $\mathrm{APH}$, address, maternal age, and number of fetuses as predictors showed that only address was a significant predictor of perinatal mortality. Newborns born to mothers with APH from Jimma town (where the study hospital is located) were 0.47 (OR) (95\% CI: 0.236 to 0.956 ) times less likely to die during their perinatal life compared to those from outside of Jimma.

\section{Maternal Outcomes}

Six (3.1\%) of the patients with APH died during the peripartum period, four of which were because of hypovolemic shock secondary to bleeding. The other two deaths were because of respiratory failure. One (1.7\%) maternal death occurred among APH cases from Jimma compared to $5(3.7 \%)$ among cases from outside of Jimma. A number of complications were diagnosed among surviving patients too. Postpartum hemorrhage and anemia (more than $10 \%$ fall in hematocrit) were the commonest postpartum complications diagnosed in $73(37.4 \%)$ and $74(38.0 \%)$ of the cases respectively. Hysterectomy was done for six (3.1\%) patients with uncontrolled postpartum hemorrhage. Thirteen (6.7\%) of the patients developed endomyometritis during postpartum period. Sixty five $(34.4 \%)$ of the patients were discharged within two days of admission; 121 (62.1\%) stayed for three to seven days; and three $(1.5 \%)$ were hospitalized for longer than a week. (Table 4)

Table 4. Maternal health outcomes, APH cases, JUSH, 2013

\begin{tabular}{cccc}
\hline Variables & Categories & Number & Percent \\
\hline \multirow{2}{*}{ Life outcome } & Discharged alive & 189 & 96.9 \\
\cline { 2 - 4 } & Maternal death & 6 & 3.1 \\
\hline & $\begin{array}{c}\text { Anemia }(>10 \% \text { drop in } \\
\text { HCT })\end{array}$ & 74 & 37.9 \\
\cline { 2 - 4 } & PPH & 73 & 37.4 \\
\cline { 2 - 4 } Complications & Endometritis & 13 & 6.7 \\
\cline { 2 - 4 } & Hysterectomy & 6 & 3.1 \\
\cline { 2 - 4 } & Respiratory failure & 2 & 1.0 \\
\cline { 2 - 4 } & Wound adhesion & 1 & 0.5 \\
\cline { 2 - 4 } & $\leq 2$ days & 65 & 33.3 \\
\hline \multirow{2}{*}{$\begin{array}{c}\text { Length of } \\
\text { hospital stay }\end{array}$} & 3 to 7 days & 121 & 62.1 \\
\cline { 2 - 4 } & $>7$ days & 3 & 1.5 \\
\hline
\end{tabular}

\section{Discussion}

The incidence of APH in JUSH was 5.1\%, 3.3\% for abruptio placentae and $1.4 \%$ for placenta previa. The incidence rates observed in JUSH were higher than reports from other studies conducted elsewhere (14, 15, 21, 27-29). This higher figure, however, doesn't directly reflect higher incidence of APH among mothers in the hospital's catchment as most uncomplicated deliveries in Ethiopia occur at home; according to the 2011 EDHS, institutional delivery rate was only $9.9 \%$ (4). Moreover, JUSH is a referral hospital where complicated cases in its catchment are more likely to be referred.

High risks of perinatal mortality $(36.9 \%)$ and maternal mortality (3.1\%) were observed among APH patients in our study hospital. In 2013, JUSH reported a total of 371 stillbirths and 31 maternal deaths (30). APH patients accounted for $63(17.0 \%)$ and $6(9.7 \%)$ of these reported perinatal and maternal deaths, respectively. Fatality rates associated with APH, both for mothers and their newborns, are tremendously higher compared to other developing and developed countries $(28,31-33)$. A retrospective study of 100 patients with AP in France for example found zero maternal deaths and only $19 \%$ perinatal death rate among APH patients in a situation where $67 \%$ of deliveries occurred prematurely (31). Our finding is in congruence with another study from Southern Ethiopia that reported very high perinatal mortality rate among newborns to patients with placenta previa and abruptio placentae (26). This suggests that adverse outcome among APH patients is a national problem requiring attention from the health sector.

Our study suggested that poor access to comprehensive obstetric care was a major contributor for the observed high fatality rates. Risks of perinatal and maternal mortality were higher for patients who came from outside of Jimma compared to patients from Jimma indicating the potential role of delay in receiving care.

The study also showed that quality of care was a problem even after a patient gets in contact with the health system. Only a quarter of patients referred to JUSH had IV line secured on referral even though they had vaginal bleeding. Blood transfusion is a lifesaving component of comprehensive emergency obstetric care for mothers with obstetric hemorrhage (34). In our study, however, we found that only $18.5 \%$ of patients were transfused with at least one unit of blood even though it was indicated for more than half of the patients. This highly conservative use of blood transfusion could possibly explain high maternal mortality in our hospital where PPH was cause of death for two third of the maternal deaths.

Prematurity was the major neonatal problem among newborns to mothers with APH in our study. Quality of neonatal resuscitation and other NICU services is therefore a critical component of the continuum of care to prevent early neonatal death. This study didn't assess the processes of care in the NICU; however, the high mortality rate among neonates admitted to NICU compared to findings from other studies $(25,28,31,33)$ is indicative of the need for improvement in quality of NICU services in the study hospital.

A major limitation of this study is associated with our inability to get information on as to how mothers who didn't make it to the study hospital were treated, get death certificates of mothers who died before they arrive to the study hospital and inability to follow discharged mothers and newborns until day seven of delivery. As a result, perinatal and maternal mortality might have been underestimated if additional deaths occurred at home among discharged 
newborns. However, even with such a limitation with a potential to underestimate mortality, the risk of perinatal and maternal mortality among APH cases in our study was much higher than findings from other studies. Therefore, the limitation won't have an impact on the validity of our conclusion.

In conclusion, APH, primarily caused by abruptio placentae and placenta previa, is a common complication of pregnancy and cause of maternal and perinatal mortality. The risk of adverse maternal and newborn outcomes including maternal mortality, perinatal mortality and low birth weight is higher among APH cases in JUSH compared to reports from other countries. Efforts to improve geographical access, referral services and quality of comprehensive emergency obstetric care are needed to improve maternal and newborn outcomes in Ethiopia.

\section{Acknowledgements}

This research is funded by Jimma University for which we are grateful. We would also like to acknowledge clients who have taken part in the research and residents involved in the data collection.

\section{REFERENCES}

[1] World Health Organization. Maternal Mortality Factsheet No 3482014 [updated May 201427 September 2014]. Available from:

http://www.who.int/mediacentre/factsheets/fs348/en/.

[2] Hogan MC, Foreman KJ, Naghavi M, Ahn SY, Wang M, Makela SM, et al. Maternal mortality for 181 countries, 1980-2008: a systematic analysis of progress towards Millennium Development Goal 5. Lancet. 2010 May 8;375(9726):1609-23. PubMed PMID: 20382417.

[3] Millennium Development Indicators: The Official United Nations Site for the MDG Indicators [Internet]. United Nations. 2014 [cited 20 September 2014]. Available from: http://mdgs.un.org/unsd/mdg/Data.aspx.

[4] Central Statistical Agency, ICF International. Ethiopia Demographic and Health Survey 2011. 2012.

[5] Central Statistical Agency, ORC Macro. Ethiopia Demographic and Health Survey 2005. 2005.

[6] Zupan J, Åhman E, World Health Organization. Neonatal and perinatal mortality : country, regional and global estimates. Geneva: World Health Organization; 2006. iv, 69 p. p.

[7] Say L, Chou D, Gemmill A, Tuncalp O, Moller AB, Daniels $\mathrm{J}$, et al. Global causes of maternal death: a WHO systematic analysis. The Lancet Global health. 2014 Jun;2(6):e323-33. PubMed PMID: 25103301.

[8] Khan KS, Wojdyla D, Say L, Gulmezoglu AM, Van Look PF. WHO analysis of causes of maternal death: a systematic review. Lancet. 2006 Apr 1;367(9516):1066-74. PubMed PMID: 16581405.

[9] Brace V, Kernaghan D, Penney G. Learning from adverse clinical outcomes: major obstetric haemorrhage in Scotland, 2003-05. BJOG : an international journal of obstetrics and gynaecology. 2007 Nov;114(11):1388-96. PubMed PMID: 17949379 .

[10] Gaym A. Maternal mortality studies in Ethiopia--magnitude, causes and trends. Ethiopian medical journal. 2009 Jan;47(2):95-108. PubMed PMID: 19743789.

[11] Ngoc NT, Merialdi M, Abdel-Aleem H, Carroli G, Purwar $\mathrm{M}$, Zavaleta N, et al. Causes of stillbirths and early neonatal deaths: data from 7993 pregnancies in six developing countries. Bulletin of the World Health Organization. 2006 Sep;84(9):699-705. PubMed PMID: 17128339. Pubmed Central PMCID: 2627466.

[12] Gardosi J, Madurasinghe V, Williams M, Malik A, Francis A. Maternal and fetal risk factors for stillbirth: population based study. Bmj. 2013;346:f108. PubMed PMID: 23349424. Pubmed Central PMCID: 3554866.

[13] Ananth CV, Smulian JC, Demissie K, Vintzileos AM, Knuppel RA. Placental abruption among singleton and twin births in the United States: risk factor profiles. American journal of epidemiology. 2001 Apr 15;153(8):771-8. PubMed PMID: 11296149.

[14] Mukherjee S, Bhide A. Antepartum Haemorrhage. Obstetrics, Gynaecology \& Reproductive Medicine. 2008;18(12):335-9.

[15] Bonnar J. Massive obstetric haemorrhage. Best Practice \& Research Clinical Obstetrics \& Gynaecology. 2000;14(1):1-18.

[16] Creasy RK, Resnik R, Iams JD. Placenta Previa and Abruptio Placentae. Maternal-fetal Medicine: Principles and Practice: Saunders; 2004.

[17] Cunningham F, Leveno K, Bloom S, Hauth J, Rouse D, Spong C. Obstetrics Hemorrhage. Williams Obstetrics: 23rd Edition: McGraw-Hill Education; 2009.

[18] Bener A, Saleh NM, Yousafzai MT. Prevalence and associated risk factors of ante-partum hemorrhage among Arab women in an economically fast growing society. Nigerian journal of clinical practice. 2012 Apr-Jun;15(2):185-9. PubMed PMID: 22718170.

[19] Miller DA, Chollet JA, Goodwin TM. Clinical risk factors for placenta previa-placenta accreta. American journal of obstetrics and gynecology. 1997 Jul;177(1):210-4. PubMed PMID: 9240608.

[20] Tikkanen M, Nuutila M, Hiilesmaa V, Paavonen J, Ylikorkala O. Prepregnancy risk factors for placental abruption. Acta obstetricia et gynecologica Scandinavica. 2006;85(1):40-4. PubMed PMID: 16521678.

[21] Ananth CV, Oyelese Y, Yeo L, Pradhan A, Vintzileos AM. Placental abruption in the United States, 1979 through 2001: temporal trends and potential determinants. American journal of obstetrics and gynecology. 2005 Jan;192(1):191-8. PubMed PMID: 15672024.

[22] Alvarez JL, Gil R, Hernandez V, Gil A. Factors associated with maternal mortality in Sub-Saharan Africa: an ecological study. BMC public health. 2009;9:462. PubMed PMID: 
20003411. Pubmed Central PMCID: 2801510.

[23] Bates I, Chapotera GK, McKew S, van den Broek N. Maternal mortality in sub-Saharan Africa: the contribution of ineffective blood transfusion services. BJOG : an international journal of obstetrics and gynaecology. 2008 Oct;115(11):1331-9. PubMed PMID: 18823485.

[24] Singla AK, Lapinski RH, Berkowitz RL, Saphier CJ. Are women who are Jehovah's Witnesses at risk of maternal death? American journal of obstetrics and gynecology. 2001 Oct;185(4):893-5. PubMed PMID: 11641673.

[25] Lawn JE, Lee AC, Kinney M, Sibley L, Carlo WA, Paul VK, et al. Two million intrapartum-related stillbirths and neonatal deaths: where, why, and what can be done? International journal of gynaecology and obstetrics: the official organ of the International Federation of Gynaecology and Obstetrics. 2009 Oct;107 Suppl 1:S5-18, S9. PubMed PMID: 19815202.

[26] Singhal S, Nymphaea, Nanda S. Maternal And Perinatal Outcome In Antepartum Hemorrhage: A Study At A Tertiary Care Referral Institute. The Internet Journal of Gynecology and Obstetrics. 2007;9(2).

[27] Berhan Y. Predictors of perinatal mortality associated with placenta previa and placental abruption: an experience from a low income country. Journal of pregnancy. 2014;2014:307043. PubMed PMID: 25002975. Pubmed Central PMCID: 4066949.

[28] Adegbola R, Okunowo A. Pattern of Antepartum Haemorrhage at the Lagos University Teaching Hospital, Lagos, Nigeria. Nigerian Medical Practitioner. 2009;56(1-2).
[29] Raksha A, Uma D. Perinatal morbidity and mortality in APH, department of Obstetrics and Gynaecology, Jawa harlal Institute of Post Graduate, Medical Education and Research Pondichery, India. 2006.

[30] Oyelese Y, Ananth CV. Placental abruption. Obstetrics and gynecology. 2006 Oct;108(4):1005-16. PubMed PMID: 17012465.

[31] JUSH. JUSH HMIS Reports, January to December 2013. 2014.

[32] Boisrame T, Sananes N, Fritz G, Boudier E, Viville B, Aissi $\mathrm{G}$, et al. [Abruptio placentae. Diagnosis, management and maternal-fetal prognosis: a retrospective study of 100 cases]. Gynecologie, obstetrique \& fertilite. 2014 Feb;42(2):78-83. PubMed PMID: 24309032. Hematome retroplacentaire. Diagnostic, prise en charge et pronostic maternofoetal: etude retrospective de 100 cas.

[33] Rasmussen S, Irgens LM, Bergsjo P, Dalaker K. Perinatal mortality and case fatality after placental abruption in Norway 1967-1991. Acta obstetricia et gynecologica Scandinavica. 1996 Mar;75(3):229-34. PubMed PMID: 8607334.

[34] Naz F, Shakoor U, Sharafat S, Khan S, Iqbal K, Zareen A. Comparison of Pregnancy Outcome in Placenta Previa versus Placenta Abruption. Pakistan Journal of Medical and Health Sciences. 2010;4(1).

[35] Campbell OM, Graham WJ, Lancet Maternal Survival Series steering g. Strategies for reducing maternal mortality: getting on with what works. Lancet. 2006 Oct 7;368(9543):1284-99. PubMed PMID: 17027735. 